\title{
Female Genital Mutilation/Cutting in Mali and Mauritania: Understanding Trends and Evaluating Policies
}

\author{
Valeria Cetorelli $^{\text {a }}{ }^{*}$, Ben Wilson ${ }^{b, c}$, Ewa Batyra ${ }^{d}$, Ernestina Coast ${ }^{\mathrm{d}}$
}

\begin{abstract}
Despite international commitments to end FGM/C, very little is known about the effectiveness of national policies in contributing to the abandonment of this harmful practice. To help address this gap in knowledge, we apply a quasi-experimental research design to study two west African countries, Mali and Mauritania. These countries have marked similarities with respect to practices of FGM/C, but differing legal contexts. A law banning FGM/C was introduced in Mauritania in 2005; in Mali there is no legal ban on FGM/C. We use nationally representative survey data to reconstruct trends in FGM/C prevalence in both countries, from 1997 to 2011, and then use a difference-in-difference method to evaluate the impact of the 2005 law in Mauritania. FGM/C prevalence in Mauritania began to decline slowly for girls born in the early 2000s, with the decline accelerating for girls born after 2005. However, a similar trend is observable in Mali, where no equivalent law has been passed. Additional statistical analysis confirms that the 2005 law did not have a significant impact on reducing FGM/C prevalence in Mauritania. These findings suggest that legal change alone is insufficient for behavioural change with regard to FGM/C. This study demonstrates how it is possible to evaluate national policies using readily available survey data in resource-poor settings.
\end{abstract}

$a$ - Middle East Centre, London School of Economics and Political Science; $b$ - Demography Unit, Department of Sociology, Stockholm University; c - Department of Methodology, London School of Economics and Political Science; $d$-Department of International Development, London School of Economics and Political Science; * Corresponding author: valeriacetorelli@gmail.com 


\section{Introduction}

Female genital mutilation/cutting (FGM/C) is recognised as a violation of human rights and harmful to girl's and women's health (Kimani, Muteshi-Strachan, and Njue 2016). FGM/C comprises "all procedures involving partial or total removal of the external female genitalia or other injury to the female genital organs for non-medical reasons" and is classified into 4 categories of varying severity (WHO 2016: 1). More than 200 million women and girls alive today are estimated to have undergone $\mathrm{FGM} / \mathrm{C}$; although there is significant variation in the practice of FGM/C between and within countries, including countries with immigrant populations from settings that have traditionally practised FGM/C. The highest FGM/C prevalence is found in west, central and north-east Africa (UNICEF 2016).

Most quantitative studies of FGM/C conduct cross-sectional analyses of a single country to describe FGM/C prevalence among girls and women (El-Gibaly et al. 2002, Jackson et al. 2003, Hayford 2005, Klouman, Manongi, and Klepp 2005, Mitike and Deressa 2009, Ouldzeidoune et al. 2013, Chikhungu and Madise 2015, Satti et al. 2013, Snow et al. 2002). There are multiple overlapping reasons why FGM/C persists and changes across time, populations and place, including: as a marker of identity, status, gender, womanhood, ethnicity or religion; for reasons of hygiene and aesthetics; and, as guarantees of honour, chastity, and marriageability (Shell-Duncan and Hernlund 2000, Shell-Duncan, Naik, and Feldman-Jacobs 2016, El-Gibaly et al. 2002, Grose et al. 2019, Hayford 2005, Mitike and Deressa 2009, Satti et al. 2013, Sayed, ElAty, and Fadel 1996, Van Der Kwaak 1992, Yount 2002, 2006, Al-Hussaini 2003). Variation in FGM/C is explained by community-specific factors, including norms and collective identity (Grose et al. 2019, Hayford 2005, Hayford and Trinitapoli 2011), although the practice is sometimes normalised to the extent that women report not knowing the reasons for having undergone the procedure (Mandara 2004).

Global and regional efforts to end FGM/C have intensified recently and calls for its elimination are supported by a wide range of bodies, including: the United Nations General 
Assembly (UNGA 2012, 2014); the African Commission on Human and Peoples' Rights Union (the "Maputo Protocol") (ACHPR 1995); the UN Commission on the Status of Women (UNESC 2011); and the European Parliament (EP 2012). The Sustainable Development Goals (SDGs) include a specific target under Goal 5 to eliminate FGM/C by 2030 (UN 2015).

At the national level, multiple stakeholders (government, civil society, communities) in some countries have made significant efforts to legislate, research, and communicate about FGM/C in order to reduce or eliminate its practice (Shell-Duncan et al. 2013, Shell-Duncan, Naik, and Feldman-Jacobs 2016, UNICEF 2013, Muthumbi et al. 2015, Rahman and Toubia 2000, Leye et al. 2007). Much of what is known is based on process accounts of interventions (WHO 1999, Chege, Askew and Liku 2001, Askew 2005, Berg and Denison 2012). There is, however, very limited knowledge about the effectiveness of national policies that have aimed to reduce FGM/C prevalence and eliminate the practice. A Ghanaian qualitative study examining the role of legal instruments in FGM/C elimination found that, despite longstanding laws criminalising FGM/C (Criminal Code [1994] and Domestic Violence Act [2003]), a lack of political support meant little effective legal implementation (Ako and Akweongo 2009). A study from rural Senegal on the implementation of a 1999 anti-FGM/C law found a range of responses that were context- and stakeholder-specific. In settings where FGM/C was being actively contested, the law was used to support that contestation; but where FGM/C was supported, evidence of the practice being driven underground and/or backlashes in response to the law were found (Shell-Duncan 2008).

There are a wide range of indicators that can be used to understand the impact of national policies on FGM/C. These range from knowledge/attitudes/perceptions (KAP) measures, to characteristics of FGM/C (type, provider, age at FGM/C), or prevalence (the proportion of women who report having undergone the procedure). The main sources of routinely collected, nationally representative and internationally comparable data on FGM/C are household surveys. Data on FGM/C status can be based on self-reports or reports of mothers about their daughters, and can be used to estimate FGM/C prevalence at different ages. Prevalence data on girls aged under 15 years can be used to assess the impact of recent FGM/C elimination efforts because this age group 
will have most recently undergone, or be at imminent risk of FGM/C. The potential limitations of self-reported data on FGM/C are well-established, including social desirability bias and lack of respondent knowledge about their status (age and type of FGM/C), particularly for those who were cut at a young age (Jackson et al. 2003). Clinical examination alongside a survey to validate self-reporting raises critical ethical issues, as it is invasive and the harms may outweigh the benefits. Limited evidence suggests that the validity of self-reporting varies, but it is generally high in settings where FGM/C is commonplace and where there are fewer influences on social desirability (Askew 2005).

FGM/C prevalence can be examined by cohort or by comparing rates across countries at specific points in time (UNICEF 2013, Yoder, Wang, and Johansen 2013). Examining long-run trends in FGM/C, both within and between countries, is essential if changes in FGM/C practices are to be understood, and if the effectiveness of FGM/C policies is to be evaluated (Muthumbi et al. 2015, Shell-Duncan, Naik, and Feldman-Jacobs 2016). Beyond description of prevalence trends, however, there is limited in-depth analysis of change in FGM/C over time. This study compares two neighbouring west African countries, Mali and Mauritania, by estimating longterm trends in FGM/C prevalence. We then analyse these trends in order to evaluate whether national policies have impacted FGM/C prevalence.

\section{[Table 1 about here]}

\section{FGM/C in Mali and Mauritania}

Mali and Mauritania are among the countries with the highest FGM/C prevalence, with $91 \%$ and $69 \%$ of women aged 15-49 years estimated as having undergone FGM/C, according to household survey data collected in 2012-2013 and 2011 respectively (Table 1). At the national level, there are marked similarities in FGM/C practices: most procedures involve cutting with flesh removal (56\% in Mali and 69\% in Mauritania); traditional practitioners do the cutting (91\% in Mali and 90\% in Mauritania); and it is most commonly performed on girls aged 0-4 years (73\% in Mali 
and $93 \%$ in Mauritania). The mean age at FGM/C is slightly higher in Mali than in Mauritania, but has decreased over time ( $78 \%$ of Malian women aged 15-19 who have undergone the procedure were cut before age 5 vs $63 \%$ of those aged 45-49). In Mali, FGM/C prevalence remains consistent across age groups (90-93\% at all ages between 15-49 years), whereas in Mauritania, prevalence is lower for younger age groups (66\% for $15-19$ years vs $75 \%$ for $45-49$ years).

In Mauritania, there are also variations in FGM/C prevalence by place of residence $(81 \%$ in rural areas $v s 57 \%$ in urban areas), education (82\% among women with no education $v s 66 \%$ among those with some education) and household wealth (94\% among the poorest $v s 48 \%$ among the richest), which are not observable in Mali. While a large proportion of women aged 15-49 reported that all of their daughters were cut (47\% in Mali and 49\% in Mauritania), a significant minority reported that some of their daughters were cut and others were not (24\% in Mali and $10 \%$ in Mauritania). The proportion of men (aged 15-64) supporting the continuation of FGM/C is almost identical in both countries, estimated at around 70\% (in 2006 for Mali and 2000-01 for Mauritania), but there are considerable differences in the proportion of women (aged 15-49) who support the continuation of FGM/C, estimated to be $73 \%$ in Mali (in 2010) and $41 \%$ in Mauritania (in 2011) (UNICEF 2013).

Mali and Mauritania share a border, and the highest prevalence FGM/C regions neighbour each other in the south-west of Mali and the south-east of Mauritania (Figure 1). The two countries also share similar social and demographic histories (especially for their bordering regions), although there are some material historical differences between them. In 2011, almost a quarter (24\%) of women aged 15-49 in Mauritania had secondary education, as compared with only 15\% in Mali in 2012-2013 (EDSM 2014, ONS 2014). Even more notable is the illiteracy rate among the female population aged 15-24, which was 83\% in Mali in 1998 and only $45 \%$ in Mauritania in 2000 (UN 2005), a difference that remains broadly similar more than ten years later (EDSM 2014, ONS 2014).

\section{[Figure 1 about here]}

Both countries have ratified several international resolutions relevant to FGM/C (Figure 
2). The Convention on the Elimination of All Forms of Discrimination Against Women (CEDAW) was ratified by Mali in 1985 and by Mauritania in 2001. The Convention on the Rights of the Child (CRC) was ratified in 1990 and 1991 respectively. The CEDAW and CRC Committees have been active in condemning FGM/C and recommending measures to combat it, including the criminalisation of the practice. Both Mali and Mauritania ratified the Maputo Protocol in 2005; Article 5 obligates signatory states to prohibit through legislative measures backed by sanctions all forms of FGM/C as well as medicalisation and paramedicalisation of the practice (UNFPA-UNICEF 2012). The 2012 UN General Assembly Resolution on Ending FGM/C and the time-bound target set as part of the 2015 SDG framework apply to both countries (UNICEF 2016).

\section{[Figure 2 about here]}

Despite many similarities in their ratification of international resolutions, Mali and Mauritania differ with respect to their national policies relating to FGM/C. The main difference is a law banning FGM/C that was introduced in Mauritania in 2005 (Figure 2). Mali has no specific national law banning FGM/C (UNFPA-UNICEF 2012, Desrumaux and Ballo 2014) and has no provisions against its medicalisation (Muthumbi et al. 2015). The Reproductive Health Law (2002) makes provision for the treatment of FGM/C (Mali 2002). Although not outlawing the practice, the Malian government has declared the elimination of FGM/C a priority (Jones et al. 1999). A National Plan for the Eradication of FGM/C (PNLE) was established in 2002; PNLE identifies several articles $(166,171,169)$ of the penal code that may prohibit FGM/C, although lack of enforcement remains an issue (28toomany 2014, Rahman and Toubia 2000). Other instruments include elements that can be applied to FGM/C. For example the Personal and Family Code (2011) has provisions that can be applied to FGM/C. Article 5 forbids the impairment of a person's physical integrity, even in the context of a religious or traditional practice, when this is harmful to the person's health (28toomany 2014) and the Family Health Act (2003) has provisions that protect children from harmful practices (Muthumbi et al. 2015). The Malian government conducted community awareness campaigns as part of the UNFPA-UNICEF Joint 
Programme on FGM/C (UNFPA-UNICEF 2012). In collaboration with the Ministry of Health and NGOs, an FGM/C curriculum was developed, tested and used to train reproductive healthcare providers and medical social workers to help them understand, identify and treat complications from FGM/C in some districts. Treatment of FGM/C complications is now included in health professionals' (doctors, nurses, midwives) curricula. Civil society organisations are active in some areas (e.g. Association Malienne pour le Suivi et l'Orientation des Pratiques Traditionnelles (AMSOPT), Tagne, Sini Sanuman), and focus on awareness-raising (religious leaders, community-level officials), alternative rites of passage and media campaigns.

By contrast, Mauritania's (2005) Children's Act specifies the harming, or attempted harm, of a female child's genitals as punishable by imprisonment and fines (Mauritania 2005). The penalty is increased if the perpetrator is a medical professional or paramedic (Ministère de la Justice 2005). Prosecutions since the Act have been rare (Sipsma et al. 2012, Ouldzeidoune et al. 2013), which may reflect a lack of clarity about the Act's purview, with some interpretations suggesting that the Act only pertains to FGM/C in government health facilities (UNICEF 2013). The Ministry of Women's Affairs (MCPFEF) works with a range of stakeholders, including civil society, to promote awareness of the law and FGM/C (Sipsma et al. 2012). Since 2005, several community awareness campaigns have been conducted by the GIZ Ending Female Genital Mutilation Programme in the south-east region of Mauritania (bordering Mali). These campaigns included interventions with religious leaders; but while a few religious leaders have publicly declared support for FGM/C eradication, there are mixed views on the issue (Worm 2013).

The critical difference between Mali and Mauritania therefore, from the perspective of understanding the impact of policy change, is that a law banning FGM/C was introduced in Mauritania in 2005. In most other respects, the two countries are broadly comparable. Both are signatories to international and regional FGM/C eradication protocols, and both countries have been identified, based on their high cross-sectional prevalence levels, as failing to meet these obligations. In both countries, there have been limited programmes to raise awareness at a range of levels (national, community), and with a range of audiences (political, religious, community, 
healthcare providers). The characteristics of FGM/C are broadly comparable across the two countries, with the vast majority of girls undergoing cutting with flesh removal by traditional practitioners below age five. The introduction of the 2005 law in Mauritania provides a timespecific point at which to identify pre- and post-policy changes in FGM/C, permitting evaluation of whether this national law has had an impact on FGM/C prevalence.

\section{Data}

Our analysis uses data from two comparable household surveys: the Demographic and Health Survey (DHS) 2012-2013 for Mali (EDSM 2014) and the Multiple Indicator Cluster Survey (MICS) 2011 for Mauritania (ONS 2014). The surveys covered a nationally representative sample of 10,105 and 10,116 households, respectively. The DHS for Mali did not include the three northern regions of Timbuktu, Gao and Kidal which account for $10 \%$ of the total population and have the lowest FGM/C prevalence (below 23\% according to the previous DHS 2006). In addition, three districts of Mopti region were also excluded for security reasons (EDSM 2014).

\section{Method}

Our analysis has four stages: (1) merging and preparing the data, (2) reconstructing trends in FGM/C prevalence by birth cohort, (3) using these trends to evaluate Mauritania's 2005 law, and (4) checking the reliability of findings by examining trends in FGM/C prevalence by year of FGM/C. We use an innovative research design that has not been applied previously to studies of FGM/C, but is broadly similar to an impact evaluation method that has been used to study other demographic and health outcomes, including adult mortality (Bendavid, Holmes et al. 2012), immunisation coverage (Cetorelli 2015) and facility-based delivery (Bendavid et al. 2012, McKinnon et al. 2014, Leone et al. 2016). Our approach is distinct from an analysis of repeated cross-sections (e.g. using several consecutive DHS or MICS) because we create a continuous time series of rates of FGM/C. Moreover, there is a considerable gap (in years) between consecutive 
nationally representative surveys, which is one important reason why we prefer the granularity of our approach, especially for the evaluation of changes in prevalence after 2005.

To create a time series of FGM/C prevalence, we harmonised all necessary variables so that the two countries can be legitimately compared. We identified all women and girls by year of birth (and age), FGM/C status (including year of FGM/C), household wealth, education, place of residence (rural or urban), and region of residence. There were no significant problems related to comparability between the surveys. However, there were some data quality issues in both the Malian DHS and Mauritanian MICS. Issues included: challenges in merging the FGM/C questions with the other data on mothers and children (MICS); a lack of consistency in age reporting across different modules of the survey (MICS); inconsistencies between the FGM/C questions and the birth history questions because birth histories are corrected during editing but corresponding edits are not made to the FGM/C questions (DHS). During our data preparation, we corresponded with the technical teams of both surveys, and made a number of quality assurance checks of our derived variables, including those relating to age and birth cohort, which are essential variables for the validity of our time series estimates.

Once the datasets were merged, we used descriptive statistical methods to estimate two different time series: (i) long-run trends in FGM/C prevalence by birth cohort, and (ii) long-run trends in new FGM/C procedures by year of FGM/C. In both cases, we accounted for the design of the national survey, including clustering and stratification (Heeringa, West, and Berglund 2010). For the trends by birth cohort, we made use of women's reports of their daughters' FGM/C status as well as information on age and year of birth, including from the women's birth histories. We calculated FGM/C prevalence by year of birth from 1997 to 2011. To supplement this trend, and provide additional evidence relating to the dynamics of FGM/C and the reliability of our results by birth cohort, we also estimated trends in new FGM/C procedures by the year at which girls underwent the procedure. We calculated the percentage of girls aged 0-4 who were cut in a given year, among girls at risk of being cut in that year. For example, the estimate for the year 2001 is the percentage of girls born between 1997 and 2001, who were cut in 2001, out of those 
girls who had not yet undergone the procedure before the year 2001. We obtained these estimates for the time period 2001-2011. Due to the unavailability of information about FGM/C of girls born before 1997, we were unable to reconstruct the corresponding trend for the time period before 2001. These trends have not previously been estimated and permit a form of robustness check for our analysis that evaluates the 2005 law.

It is important to keep in mind, however, that the two trends are not comparable, not least because they represent distinctly different populations in any given year (i.e. they are rates with different denominators). There are also some data quality issues with the reporting of year at FGM/C. The year of FGM/C is approximated and calculated by adding the age at FGM/C to year of birth. Women may be more likely to report accurately about their daughters' age (and hence their birth cohort) than their daughters' age at FGM/C. Further, the age at FGM/C variable in DHS and MICS has a category "at birth/in infancy" that does not specify how many months after birth the procedure took place. In these cases, girls were classified as if they underwent FGM/C in the same year as year of birth. Furthermore, there is a larger proportion of missing values in Mali (8\%) than in Mauritania (1\%).

Next, we evaluated the impact of the Mauritanian legislation introduced in 2005. We used a difference-in-difference (DID) method that allowed us to extract the maximum utility from existing data in order to better understand the impact of a national FGM/C law. This method is often used for policy evaluation, including evaluation of AIDS relief programmes and user fees for health service removal (Bendavid et al. 2012, McKinnon et al. 2014, Leone et al. 2016). Our implementation of DID uses statistical analysis to calculate the effect of a policy (here, the 2005 Mauritanian law) on an outcome (FGM/C prevalence) by comparing the average change over time in prevalence in Mauritania to the average change over time in Mali. The impact of the Mauritanian 2005 law is therefore evaluated by contrasting trends in FGM/C prevalence before and after the implementation of the law, using Mali as the counterfactual country that has not introduced similar legislation.

This use of a counterfactual, in addition to examining changes in prevalence over time, 
explains why DID is a more powerful tool to understand the impact of a policy than other, more simple techniques. For example, an analysis of change over time (pre- vs post-policy) for Mauritania alone would need to assume that there are no factors (e.g. social or religious change), other than the law, that impact changes in FGM/C prevalence. Similarly, a cross-sectional comparison of Mali and Mauritania would be equally unsatisfactory because it assumes that there are no differences between the two countries. Our DID approach uses time series data to measure the differences between the 'policy-exposed' country (Mauritania) and the 'unexposed' counterfactual (Mali), in their changing FGM/C prevalence. By estimating the impact in this way, we do not need to measure all of the differences between the two countries. Our approach means that our results are net of all fixed differences between the two countries, and therefore far less likely to be explained by any variable that is omitted. One potential source of bias relates to the main identification assumption of DID, namely that the trends between the two countries are 'parallel' in absence of the 2005 legislation. We examine this assumption, while noting that it cannot be tested directly. In summary, we argue that DID represents the most robust approach available for evaluating the impact of a national policy using routinely collected data.

Our analysis is made possible due to the fact that most girls in Mauritania and Mali undergo FGM/C when they are $0-4$ years old (Table 1). This means that we are able to compare groups of girls who were at risk of undergoing FGM/C before 2005 with those at risk after 2005. First, we compare girls born in 1999-2000 (who were at least 4 years old when the law was introduced) with girls born in 2006-2007 (who were at least 4 years old at the time of the surveys). We then perform the DID analysis by birth cohort focussing on the high FGM/C prevalence border regions of Mali and Mauritania. This is important because it may be a more valid comparison than simply a national-level comparison. These border regions are far more likely to be similar to each other (than the two countries overall) in a range of aspects, not least with respect to their baseline FGM/C prevalence. Finally, we examine the reliability of our findings by calculating the DID estimate for year of FGM/C, rather than birth cohort. We compare new FGM/C procedures among girls aged 0-4 in 2004 (the year before the introduction of the law) 
with new FGM/C procedures among girls aged 0-4 in 2006 (the year after the introduction of the law), both at the national level and in the high prevalence border regions.

We use a linear probability model to estimate the impact of the 2005 Mauritanian law on FGM/C. This allows for a straightforward interpretation of the DID coefficient as the average causal effect of the 2005 legislation. The model is specified as:

$$
\mathrm{Y}_{\mathrm{i}}=\beta^{\prime} \mathrm{X}_{\mathrm{i}}+\gamma_{\mathrm{i}}+\delta_{\mathrm{i}}+\zeta \mathrm{L}_{\mathrm{i}}+\varepsilon_{\mathrm{i}}
$$

where $Y_{i}$ is a binary outcome variable referring to $\mathrm{FGM} / \mathrm{C}$ status for girl $\mathrm{i}$. The variable is coded 1 if the girl has undergone $\mathrm{FGM} / \mathrm{C}$, as reported by her mother, and 0 otherwise. $\mathrm{X}_{\mathrm{i}}$ is a vector of available characteristics in the datasets that may influence FGM/C, including mother's education (no education $v s$ some education), household wealth (poorest, poor, middle, rich, and richest) and place of residence (rural $v s$ urban). This vector also includes region fixed effects and year of birth fixed effects. $\gamma_{1}$ is a country indicator coded 1 if the girl was born in Mauritania, and 0 if she was born in Mali. $\delta_{\mathrm{1}}$ is a period indicator coded 1 if the girl was at risk of undergoing FGM/C after 2005, and 0 if she was at risk before 2005. Finally, $\mathrm{L}_{\mathrm{i}}$ is an interaction term between the country and period indicators, coded 1 if the girl was born in Mauritania and was at risk of undergoing the procedure after 2005 , and 0 otherwise. The associated coefficient $\zeta$ estimates the net effect of the 2005 legislation on FGM/C prevalence. $\varepsilon_{\mathrm{i}}$ is a random, idiosyncratic error term. All models are estimated by OLS in Stata (version 13), and we use the same software to account for survey design in the FGM/C trends (using the 'SVY' command).

\section{Results}

Pre-2005 trends in FGM/C prevalence by birth cohort in Mali and Mauritania were parallel and relatively stable (Figure 3). The average difference between the two countries was 21 percentage points among girls born between 1997 and 2004. After 2005, FGM/C prevalence fell in both Mali and Mauritania, with a slightly faster decline in Mali. The average difference between the two countries was 16 percentage points among girls born between 2006 and 2011. This initial 
assessment suggests that the introduction of the 2005 law in Mauritania did not affect FMG/C prevalence. The survey dates of 2011 in Mauritania and 2012-2013 in Mali result in censored observations for the later birth cohorts. For example, girls born in 2010 have FGM/C data on average through only about the first one year of life in Mauritania and through age $2 \frac{1}{2}$ years in Mali. Therefore, the decline in FGM/C prevalence seen in the later birth cohorts may be due to the fact that there is progressively less and less time for girls in each cohort to have undergone FGM/C.

Table 2 presents estimates from national DID regression models. These models overcome the truncated cohort bias by comparing girls born in 1999-2000 who were at least 4 years old when the Mauritanian law was introduced with girls born in 2006-2007 who were at least 4 years old at the time of the surveys. Model 1 controls for country and period fixed effects, Model 2 adds region and year of birth fixed affects, and Model 3 adds household characteristics. All models confirm no significant impact of the 2005 law on national FGM/C prevalence in Mauritania. Mother's education is the only covariate to be significantly associated with FGM/C. Girls whose mothers had some education are 6 percentage points less likely to have undergone FGM/C compared with girls whose mothers had no education. Household wealth and place of residence do not appear to have an effect, once controlling for the other factors included in the models. Although these covariates are associated with levels of prevalence, they do not appear to be associated with conditional changes in prevalence (which is the outcome modelled here).

\section{[Figure 3 about here]}

\section{[Table 2 about here]}

In order to understand whether the impact of the law was differential at the subnational level, we estimate trends in the high FGM/C prevalence border regions in south-west Mali and south-east Mauritania. Trends appear very similar between these bordering regions; FGM/C prevalence was stable before 2005 but declined thereafter (Figure 4). The average prevalence was 8 percentage points higher in south-east Mauritania than in south-west Mali among girls born 
between 1997 and 2004, and 11 percentage points higher in south-east Mauritania than in southwest Mali among girls born between 2006 and 2011.

Table 3 reports DID regression models for the 1999-2000 and 2006-2007 birth cohorts in the high FGM/C prevalence border regions. Model 4 controls for country and period fixed effects, Model 5 adds region and year of birth fixed affects, and Model 6 adds household characteristics. We find no impact of the 2005 law in the high FGM/C prevalence border regions. In these regions the only household characteristic to be significantly associated with FGM/C is mother's education, mirroring the national level analysis.

\section{[Figure 4 about here]}

\section{[Table 3 about here]}

To check the reliability of our findings, we also examine trends in FMG/C prevalence by year of FGM/C. It is important to keep in mind that these trends are not easily compared with trends in FGM/C prevalence by birth cohort, not least because their denominators are different. Trends in FGM/C prevalence by year of FGM/C appear to be similar in Mali and Mauritania before the introduction of the law (Figure 5). Between 2001 and 2004, the average prevalence was 5 percentage points higher in Mali than in Mauritania. After 2005, the rate of decline in FGM/C prevalence appears more rapid in Mauritania than in Mali, with the average difference widening to 11 percentage points between 2006 and 2011. In the high prevalence border regions in south-east Mauritania and south-west Mali, trends in FGM/C prevalence by year of FGM/C were stable and parallel before 2005 (Figure 6). Prevalence was 27 percentage points higher in south-east Mauritania than in south-west Mali between 2001 and 2004. After the introduction of the law, prevalence declined faster in south-east Mauritania than in south-west Mali; the average difference narrowed to 17 percentage points between 2006 and 2011.

Table 4 reports estimates from DID models quantifying the impact of the 2005 Mauritanian law by comparing girls aged 0-4 who were at risk of undergoing FGM/C in 2004 with girls aged 0-4 who were at risk of undergoing the procedure in 2006. Model 7 controls for country and period fixed effects, Model 8 adds region and year of birth fixed affects, and Model 
9 adds household characteristics. Table 5 presents DID regression models for the high prevalence border regions with the same sets of controls. All models show no significant impact of the 2005 law, either at the national level or in the high prevalence border regions.

\section{[Figure 5 about here] \\ [Figure 6 about here] \\ [Table 4 about here] \\ [Table 5 about here]}

\section{Discussion}

Despite increased commitments to end FMG/C, very little is known about the effectiveness of national policies in contributing to the abandonment of this harmful practice. As efforts to reduce and eliminate FGM/C are developed, their impact needs to be evaluated and understood. Much of what we know is based on descriptive process accounts of interventions, rather than impact evaluations on outcomes such as FGM/C prevalence. To contribute to filling this research gap, we focused on two west African countries - Mali and Mauritania - that have marked similarities with respect to FGM/C. The vast majority of girls in Mali and Mauritania undergo cutting with flesh removal by traditional practitioners below age five; and the highest FGM/C prevalence regions neighbour each other in south-west Mali and south-east Mauritania. Both countries are signatories to international and regional FGM/C eradication protocols and have implemented limited national and community awareness-raising campaigns with a range of audiences. The critical difference between the two countries is that a law banning FGM/C was introduced in Mauritania in 2005.

To understand whether the introduction of this law has had an impact on FGM/C prevalence at the national level and/or in the highest prevalence regions, we adopted an innovative research design which extracts the maximum utility from routinely collected household survey data. The supply of, and demand for, household survey data has accelerated in recent years 
(Demombynes Sandefur 2014) and it is critical for the design, monitoring and evaluation of effective policies to make more and better use of such data (UN 2014). Our analyses made novel use of DHS and MICS data, including a critical assessment of the quality of these data. We used mother's reports of the FGM/C status of living daughters aged under 15 to reconstruct trends in FGM/C prevalence by birth cohort and by year of FGM/C. We then contrasted trends in FGM/C prevalence in Mauritania before and after the introduction of the law, using Mali as a counterfactual.

FGM/C prevalence in Mauritania began to decline slowly among girls born in the early 2000s, with the decline accelerating for girls born post-2005. However, a similar trend is observable in Mali, where no equivalent law was present. Trends by birth cohort were very similar in the border regions of the two countries, with a decline in FGM/C prevalence among girls born after 2005 observable in south-east Mali and south-west Mauritania. The rate of decline was slightly faster in Mali than in Mauritania after 2005. In a slight reversal of this pattern, trends by year of FGM/C showed a relatively faster decline in Mauritania than in Mali after 2005, both at the national level and in the high prevalence border regions. Despite this, all of our DID models suggest that the 2005 law did not have a significant impact on reducing FGM/C prevalence in Mauritania. It is possible that six years, which is the maximum follow-up permitted by our data, is too short for the policy change to have an identifiable impact. Further insights may therefore be gained from research that evaluates a longer follow-up period.

Our findings suggest that additional evidence, including rigorous implementation research, is needed in order to establish why this new law in Mauritania does not yet appear to have had any effect. Evidence from a Mauritanian intervention to raise awareness of the law change among religious leaders suggests that while some religious leaders have publicly denounced FGM/C post-2005, there are mixed views on the issue, including that FGM/C is a religious obligation or acceptance of medicalised FGM/C (Worm, 2013). On the other hand, it may be that the law has already had an impact on non-behavioural measures, such as social norms, rather than actual FGM/C practices. Further research could build upon these findings and cast 
light upon the pathway from national legislation to norms, attitudes and behaviours. This may help to establish the extent to which our findings are generalisable beyond this West African context, which may or may not be the case. Indeed, one avenue for research might be to examine differences between countries in the content, enactment and enforcement of FGM/C legislation. Our analysis is unable to disentangle the different aspects of the ordinance prohibiting FGM/C in Mauritania, but as discussed earlier, the content of the legislation is complex, as is likely to be its interaction with the social, political and historical context in the country.

Despite this, our analyses do demonstrate that legal change alone may be insufficient for behaviour change. A recent descriptive assessment of trends in child marriage prevalence in 31 African countries has reached a similar conclusion, that laws setting the minimum legal age for marriage at 18 years or older are insufficient to eliminate this harmful practice (Koski, Clark and Nandi 2017). However, legal changes are a critical and necessary first step and facilitate subsequent changes, including law enforcement, knowledge diffusion, and behaviour change, such that their effects might not be observable in the short-run. Whether a law is known (e.g. by the general population, professional and socio-cultural communities, law enforcers, etc.), accepted, or contested, are equally critical components. Simply having a law on the statute books is no guarantee that FGM/C prevalence will decline. Broader changes across a wide range of domains - socio-cultural, religious, educational, gender-based, organisational, and with respect to law enforcement - are also needed.

Our analyses also highlight the need for more careful assessments of the attribution of declines in FMG/C prevalence, moving beyond simplistic change over time (pre- $v s$ post-policy) for one country alone or using cross-sectional comparison between countries. With a more nuanced research design, it is possible to examine national and subnational trends in FGM/C, including for the evaluation of national policies. Moreover, nationally representative survey data, like DHS and MICS, provide sufficiently large sample sizes and robust quality data across population sub-groups, that cannot be otherwise obtained cost-effectively in resource-poor settings. 


\section{References}

28toomany. 2014. Country profile: FGM in Mali.

ACHPR. 1995. Protocol to the African Charter on Human and Peoples' Rights on the Rights of Women in Africa. edited by African Commission on Human and Peoples' Rights. Addis Ababa: African Commission on Human and Peoples' Rights.

Ako, M. A., and P. Akweongo. 2009. "The limited effectiveness of legislation against female genital mutilation and the role of community beliefs in Upper East Region, Ghana." Reproductive Health Matters 17 (34):47-54.

Al-Hussaini, T. K. 2003. "Female genital cutting: types, motives and perineal damage in laboring Egyptian women." Medical Principles and Practice 12 (2):123-128.

Askew, I. 2005. "Methodological issues in measuring the impact of interventions against female genital cutting." Culture, Health and Sexuality 7(5):463-477.

Bendavid, E., C. B. Holmes, J. Bhattacharya, and G. Miller. 2012. "HIV development assistance and adult mortality in Africa." JAMA 307 (19):2060-2067.

Berg, R., and E. Denison. 2012 "Interventions to reduce the prevalence of female genital mutilation/cutting in African countries." The Campbell Collaboration.

Boyle, E.H., and S. E. Preves. 2000. "National politics as international process: the case of antifemale-genital-cutting laws." Law and Society Review 34(3):703-737.

Cetorelli, V. 2015. "The impact of the Iraq War on neonatal polio immunisation coverage: a quasi-experimental study." Journal of Epidemiology and Community Health 69(3):226231.

Chege, J., I. Askew, J. Liku. 2001. "An Assessment of the Alternative Rites Approach for Encouraging Abandonment of Female Genital Mutilation in Kenya." Nairobi: Population Council.

Chikhungu, L. C., and N. J. Madise. 2015. "Trends and protective factors of female genital mutilation in Burkina Faso: 1999 to 2010." International Journal for Equity in Health 14 $(1): 1$. 
Demombynes, G., and J. Sandefur. 2014. "Costing a data revolution." Center for Global Development Working Paper 383.

Desrumaux, A., and B. Ballo. 2014. "«Protéger la Prochaine Génération»: promouvoir l'abandon des mutilations génitales féminines dans le district sanitaire de Kayes au Mali." Santé Publique 1 (HS):51-58.

EDSM. 2014. Mali: Enquête Démographique et de Santé (EDSM-V) 2012-2013. Cellule de Planification et de Statistiques (CPS/SSDSPF), Institut National de la Statistique (INSTAT), Centre d'Études et d'Information Statistiques (INFO-STAT), ICF International.

El-Gibaly, O., B. Ibrahim, B. S. Mensch, and W. H. Clark. 2002. "The decline of female circumcision in Egypt: evidence and interpretation." Social Science and Medicine 54 (2):205-220.

EP. 2012. European Parliament resolution of 14 June 2012 on ending female genital mutilation. Edited by European Parliament. Strasbourg.

Grose, R. G., Hayford, S. R., Cheong, Y. F., Garver, S., Kandala, N.-B. and Yount, K. M. 2019. "Community Influences on Female Genital Mutilation/Cutting in Kenya: Norms, Opportunities, and Ethnic Diversity." Journal of Health and Social Behavior, 60(1): 84100.

Hassanin, M. I., R. Saleh, A. A. Bedaiwy, R. S. Peterson, and M. A. Bedaiwy. 2008. "Prevalence of female genital cutting in Upper Egypt: 6 years after enforcement of prohibition law." Reproductive Biomedicine Online 16:27-31.

Hayford, S. R. 2005. "Conformity and change: community effects on female genital cutting in Kenya." Journal of Health and Social Behavior 46 (2):121-140.

Hayford, S. R. and Trinitapoli, J. 2011. "Religious Differences in Female Genital Cutting: A Case Study from Burkina Faso." Journal for the Scientific Study of Religion, 50(2): 252271.

Heeringa, S. G., B. T. West, and P. A. Berglund. 2010. Applied survey data analysis. London: 
Chapman and Hall.

ICF. 2012. "Survey Organization Manual." Calverton, MD, DHS: ICF International.

Jackson, E. F., P. Akweongo, E. Sakeah, A. Hodgson, R. Asuru, and J. F. Phillips. 2003. "Inconsistent reporting of female genital cutting status in northern Ghana: Explanatory factors and analytical consequences." Studies in Family Planning 34 (3):200-210.

Jones, H., N. Diop, I. Askew, and I. Kaboré. 1999. "Female genital cutting practices in Burkina Faso and Mali and their negative health outcomes." Studies in Family Planning 30 (3):219-230.

Kimani, S., J. Muteshi-Strachan, and C. Njue. 2016. Health impacts of female genital mutilation/cutting: A synthesis of the evidence. Population Council.

Klouman, E., R. Manongi, and K- I. Klepp. 2005. "Self- reported and observed female genital cutting in rural Tanzania: Associated demographic factors, HIV and sexually transmitted infections." Tropical Medicine and International Health 10 (1):105-115.

Koski, A., S. Clark, A. Nandi. 2017. "Has child marriage declined in sub-Saharan Africa? An analysis of trends in 31 countries." Population and Development Review 43(1):7-29.

Leone, T., V. Cetorelli, S. Neal, and Z. Matthews. 2016. "Financial accessibility and user fee reforms for maternal healthcare in five sub-Saharan countries: a quasi-experimental analysis." BMJ Open 6 (1):e009692.

Leye, Els, Jessika Deblonde, José García-Añón, Sara Johnsdotter, Adwoa Kwateng-Kluvitse, Linda Weil-Curiel, and Marleen Temmerman. 2007. "An analysis of the implementation of laws with regard to female genital mutilation in Europe." Crime, Law and Social Change 47 (1):1-31. doi: 10.1007/s10611-007-9055-7.

Mali. 2002. Santé de la reproduction. In 02-044, edited by République du Mali Présidence de la République Bamako.

Mandara, M. U. 2004. "Female genital mutilation in Nigeria." International Journal of Gynecology and Obstetrics 84 (3):291-298.

Mauritania. 2005. Portant Protection Pénale de Lenfant. In Ordonnance $\mathrm{N}^{\circ} 2005-015$, edited by 
Ministère de la Justice.

McKinnon, B., S. Harper, J. S. Kaufman, and Y. Bergevin. 2014. "Removing user fees for facility-based delivery services: a difference-in-differences evaluation from ten subSaharan African countries." Health Policy and Planning 30:432-441.

Mitike, G., and W. Deressa. 2009. "Prevalence and associated factors of female genital mutilation among Somali refugees in eastern Ethiopia: a cross-sectional study." BMC Public Health 9 (1):1.

Muthumbi, J., J. Svanemyr, E. Scolaro, M. Temmerman, and L. Say. 2015. "Female Genital Mutilation: A Literature Review of the Current Status of Legislation and Policies in 27 African Countries and Yemen." African Journal of Reproductive Health 19 (3):32-40.

ONS. 2014. Suivi de la situation des femmes et des enfants: Enquête par grappes à indicateurs multiples - MICS4 - 2011. Office National De La Statistique (ONS). MICS.

Ouldzeidoune, N., J. Keating, J. Bertrand, and J. Rice. 2013. "A description of female genital mutilation and force-feeding practices in Mauritania: implications for the protection of child rights and health." PLOS One 8 (4):e60594.

Rahman, Anika, and Nahid Toubia. 2000. Female genital mutilation: A practical guide to worldwide laws \& policies: Zed Books.

Satti, A., S. Elmusharaf, H. Bedri, T. Idris, M. S. K. Hashim, G. I. Suliman, and L. Almroth. 2013. "Prevalence and determinants of the practice of genital mutilation of girls in Khartoum, Sudan." Annals of Tropical Paediatrics: International Child Health 26 (4):303310.

Sayed, G. H., M. A. Abd El-Aty, and K. A. Fadel. 1996. "The practice of female genital mutilation in Upper Egypt." International Journal of Gynecology and Obstetrics 55 (3):285-291.

Shell-Duncan, B., R. Naik, and C. Feldman-Jacobs. 2016. A state-of-the-art synthesis on female genital mutilation/cutting. What do we know now? In Evidence to End FGM/C: Research to Help Women Thrive. New York: Population Council. 
Shell-Duncan, B. 2008. "From Health to Human Rights: Female Genital Cutting and the Politics of Intervention." American Anthropologist 110 (2):225-236. doi: 10.1111/j.15481433.2008.00028.x.

Shell-Duncan, B., and Y. Hernlund. 2000. Female" circumcision" in Africa: culture, controversy, and change: Lynne Rienner Publishers.

Shell- Duncan, B., K. Wander, Y. Hernlund, and A. Moreau. 2013. "Legislating change? Responses to criminalizing female genital cutting in Senegal." Law \& Society Review 47 (4):803-835.

Sipsma, Heather L, Peggy G Chen, Angela Ofori-Atta, Ukwuoma O Ilozumba, Kapouné Karfo, and Elizabeth H Bradley. 2012. "Female genital cutting: current practices and beliefs in western Africa." Bulletin of the World Health Organization 90 (2):120-127.

Snow, R. C., T. E. Slanger, F. E. Okonofua, F. Oronsaye, and J. Wacker. 2002. "Female genital cutting in southern urban and peri- urban Nigeria: self- reported validity, social determinants and secular decline." Tropical Medicine and International Health 7 (1):91100.

Toubia, N., E. Sharief. 2003. "Female genital mutilation: have we made progress?" International Journal of Gynaecology and Obstetrics, 82:251-261.

UN. 2005. "The World's Women reports: Table 4c - Illiteracy"

[ST/ESA/STAT/SER.K/WWW/16/Rev.5 - 24 August 2005], accessed from: https://unstats.un.org/unsd/demographic/products/indwm/ww2005/tab4c.htm

UN. 2014. A world that counts: mobilising the data revolution for sustainable development. Report prepared at the request of the UN Secretary-General by the Independent Expert Advisory Group on a Data Revolution for Sustainable Development.

UN. 2015. Transforming Our World: The 2030 Agenda for Sustainable Development. United Nations.

UNESC. 2011. Ending female genital mutilation. Report of the Secretary-General. New York: United Nations Economic and Social Council. 
UNFPA-UNICEF. 2012. Joint Programme on female Genital Mutilation / Cutting: Accelerating Change. Annual Report. New York: UNFPA \& UNICEF.

UNGA. 2012. "67/146. Intensifying global efforts for the elimination of female genital mutilations." United Nations General Assembly Accessed 15/11/2017. http://www.un.org/ga/search/view_doc.asp?symbol=A/RES/67/146.

UNGA. 2014. 69/150. Intensifying global efforts for the elimination of female genital mutilations edited by United Nations General Assembly. New York: United Nations.

UNICEF. 2013. Female genital mutilation/cutting: a statistical overview and exploration of the dynamics of change.

UNICEF. 2016. Female Genital Mutilation/Cutting: A Global Concern. New York, NY: UNICEF.

Van Der Kwaak, Anke. 1992. "Female circumcision and gender identity: A questionable alliance?" Social Science and Medicine 35 (6):777-787.

WHO. 2016. Female genital mutilation fact sheet.

WHO. 2010. Global strategy to stop health-care providers from performing female genital mutilation: UNAIDS, UNDP, UNFPA, UNHCR, UNICEF, UNIFEM, WHO, FIGO, ICN, IOM, MWIA, WCPT, WMA. Geneva: WHO.

WHO. 2008. Eliminating female genital mutilation: an interagency statement; OHCHR, UNAIDS, UNDP, UNECA, UNESCO, UNFPA, UNHCR, UNIFEM, WHO. Geneva: WHO.

WHO. 1999. Female Genital Mutilation Programmes to Date: What Works and What Doesn't. Geneva: WHO.

Worm, I. 2013. Female genital mutilation in Mauritania: Stengthening the competence of religious leaders to bring the practice to an end: Summary of experiences - GIZ report on the supra-regional prioject "Ending female genital mutilation". Eschborn, Germany: Gesellschaft für Internationale Zusammenarbeit (GIZ) GmbH.

Yoder, P. S., S. Wang, and E. Johansen. 2013. "Estimates of female genital mutilation/cutting in 
27 African countries and Yemen." Studies in Family Planning 44:189-204.

Yount, K. M. 2002. "Like Mother, like Daughter? Female Genital Cutting in Minia, Egypt." Journal of Health and Social Behavior 43 (3):336-358. doi: 10.2307/3090208.

Yount, K. M. 2004. "Symbolic Gender Politics, Religious Group Identity, and the Decline in Female Genital Cutting in Minya, Egypt." Social Forces, 82(3): 1063-1090.

\section{Acknowledgments}

The authors would like to acknowledge the DHS and MICS data support teams for their assistance with this research.

\section{Funding}

This work was supported by an LSE STICERD grant. 
TABLE 1 Comparison of Mali and Mauritania

\begin{tabular}{|c|c|c|}
\hline Indicator & Mali & Mauritania \\
\hline \multicolumn{3}{|l|}{ Women aged 15-49 who have undergone FGM/C (\%) } \\
\hline All women $15-49$ & 91 & 69 \\
\hline $45-49$ & 92 & 75 \\
\hline $40-44$ & 93 & 76 \\
\hline $35-39$ & 91 & 72 \\
\hline $30-34$ & 91 & 72 \\
\hline $25-29$ & 93 & 68 \\
\hline $20-24$ & 91 & 66 \\
\hline $15-19$ & 90 & 66 \\
\hline Rural & 92 & 81 \\
\hline Urban & 90 & 57 \\
\hline Woman has no education & 92 & 82 \\
\hline Woman has some education & 90 & 66 \\
\hline Richest (top quintile, based on household wealth index) & 91 & 48 \\
\hline Rich & 92 & 57 \\
\hline Middle & 92 & 73 \\
\hline Poor & 92 & 88 \\
\hline Poorest & 90 & 94 \\
\hline \multicolumn{3}{|l|}{ Age at which FGM/C occurred among women aged 15-49 (\%) } \\
\hline 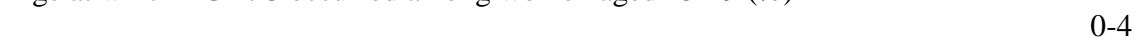 & 73 & 93 \\
\hline $5-9$ & 15 & 1 \\
\hline $10-14$ & 7 & 0 \\
\hline $15+$ & 0 & 0 \\
\hline $\mathrm{DK} / \mathrm{missing}$ & 5 & 6 \\
\hline \multicolumn{3}{|l|}{ Person performing FGM/C among women aged 15-49 (\%) } \\
\hline Traditional practitioner & 91 & 90 \\
\hline Health personnel & 1 & 1 \\
\hline $\mathrm{DK} / \mathrm{missing}$ & 8 & 9 \\
\hline \multicolumn{3}{|l|}{ Type of FGM/C among women aged 15-49 (\%) * } \\
\hline Cut, flesh removed & 56 & 69 \\
\hline Cut, no flesh removed/Nicked & 14 & 2 \\
\hline DK/missing & 29 & 29 \\
\hline \multicolumn{3}{|l|}{ Daughters' FGM/C status among women aged $15-49(\%)$} \\
\hline All of their daughters were cut & 47 & 49 \\
\hline Some daughters were cut, others were not & 24 & 10 \\
\hline None of their daughters were cut & 29 & 41 \\
\hline
\end{tabular}

Note: This analysis uses the survey design, including survey weights, and is therefore representative of the national populations.

* Approximately $1 \%$ of women in Mali report their type of FGM/C as 'sewn closed', some of whom also report themselves as 'cut, flesh removed.'

Sources: Mauritania MICS 2011 and Mali DHS 2012-2013 
TABLE 2 DID regression: Mauritania compared with Mali, birth cohorts 1999-2000 and 2006-2007

\begin{tabular}{|c|c|c|c|}
\hline & \multirow{2}{*}{ (1) } & \\
\hline & & $(2)$ & (3) \\
\hline Impact of anti-FGM/C law & $0.01(-0.07 ; 0.08)$ & $0.02(-0.05 ; 0.08)$ & $0.02(-0.04 ; 0.08)$ \\
\hline \multicolumn{4}{|l|}{ Place of residence } \\
\hline Rural (ref. category) & & & - \\
\hline Urban & & & $0.02(-0.05 ; 0.10)$ \\
\hline \multicolumn{4}{|l|}{ Household wealth } \\
\hline Poorest (ref. category) & & & - \\
\hline Poorer & & & $0.01(-0.05 ; 0.06)$ \\
\hline Middle & & & $-0.04(-0.09 ; 0.03)$ \\
\hline Richer & & & $-0.05(-0.14 ; 0.04)$ \\
\hline Richest & & & $-0.06(-0.18 ; 0.06)$ \\
\hline \multicolumn{4}{|l|}{ Mother's education } \\
\hline No education (ref. category) & & & - \\
\hline Some education & & & $-0.06^{* *}(-0.11 ;-0.02)$ \\
\hline Country indicator & Yes & Yes & Yes \\
\hline Period indicator & Yes & Yes & Yes \\
\hline Region fixed effects & No & Yes & Yes \\
\hline Year of birth fixed effects & No & Yes & Yes \\
\hline
\end{tabular}

Estimates from Mauritania MICS 2011 and Mali DHS 2012-2013

The $95 \%$ CIs in parentheses are derived from robust SEs clustered at the region level $* \mathrm{p}<0.05 * * \mathrm{p}<0.01 * * * \mathrm{p}<0.001$ 
TABLE 3 DID regression: High prevalence border regions, birth cohorts 1999-2000 and 2006-2007

\begin{tabular}{|c|c|c|c|}
\hline & \multirow[b]{2}{*}{ (4) } & \multirow[b]{2}{*}{ (5) } & \multirow[b]{2}{*}{$(6)$} \\
\hline & & & \\
\hline Impact of anti-FGM/C law & $0.03(-0.01 ; 0.06)$ & $0.02(-0.02 ; 0.07)$ & $0.03(-0.02 ; 0.07)$ \\
\hline \multicolumn{4}{|l|}{ Place of residence } \\
\hline Rural (ref. category) & & & - \\
\hline Urban & & & $0.03(-0.10 ; 0.16)$ \\
\hline \multicolumn{4}{|l|}{ Household wealth } \\
\hline Poorest (ref. category) & & & - \\
\hline Poorer & & & $0.00(-0.08 ; 0.08)$ \\
\hline Middle & & & $-0.03(-0.15 ; 0.09)$ \\
\hline Richer & & & $-0.03(-0.25 ; 0.19)$ \\
\hline Richest & & & $-0.01(-0.24 ; 0.27)$ \\
\hline \multicolumn{4}{|l|}{ Mother's education } \\
\hline No education (ref. category) & & & - \\
\hline Some education & & & $-0.08 *(-0.13 ;-0.02)$ \\
\hline Country indicator & Yes & Yes & Yes \\
\hline Period indicator & Yes & Yes & Yes \\
\hline Region fixed effects & No & Yes & Yes \\
\hline Year of birth fixed effects & No & Yes & Yes \\
\hline
\end{tabular}

Estimates from Mauritania MICS 2011 and Mali DHS 2012-2013

The $95 \%$ CIs in parentheses are derived from robust SEs clustered at the region level ${ }^{*} \mathrm{p}<0.05 * * \mathrm{p}<0.01 * * * \mathrm{p}<0.001$ 
TABLE 4 DID regression: Mauritania compared with Mali, FGM/C years 2004 and 2006

\begin{tabular}{|c|c|c|c|}
\hline & \\
\hline & $(7)$ & $(8)$ & $(9)$ \\
\hline Impact of anti-FGM/C law & $-0.01(-0.05 ; 0.04)$ & $0.03(-0.01 ; 0.07)$ & $0.03(-0.01 ; 0.07)$ \\
\hline \multicolumn{4}{|l|}{ Place of residence } \\
\hline Rural (ref. category) & & & - \\
\hline Urban & & & $-0.00(-0.05 ; 0.06)$ \\
\hline \multicolumn{4}{|l|}{ Household wealth } \\
\hline Poorest (ref. category) & & & - \\
\hline Poorer & & & $0.02(-0.03 ; 0.07)$ \\
\hline Middle & & & $-0.03(-0.08 ; 0.02)$ \\
\hline Richer & & & $-0.02(-0.09 ; 0.05)$ \\
\hline Richest & & & $-0.03(-0.12 ; 0.07)$ \\
\hline \multicolumn{4}{|l|}{ Mother's education } \\
\hline No education (ref. category) & & & - \\
\hline Some education & & & $-0.02(-0.05 ; 0.01)$ \\
\hline Country indicator & Yes & Yes & Yes \\
\hline Period indicator & Yes & Yes & Yes \\
\hline Region fixed effects & No & Yes & Yes \\
\hline Year of birth fixed effects & No & Yes & Yes \\
\hline
\end{tabular}

Estimates from Mauritania MICS 2011 and Mali DHS 2012-2013

The $95 \%$ CIs in parentheses are derived from robust SEs clustered at the region level

${ }^{*} \mathrm{p}<0.05 * * \mathrm{p}<0.01 * * * \mathrm{p}<0.001$ 
TABLE 5 DID regression: High prevalence border regions, FGM/C years 2004 and 2006

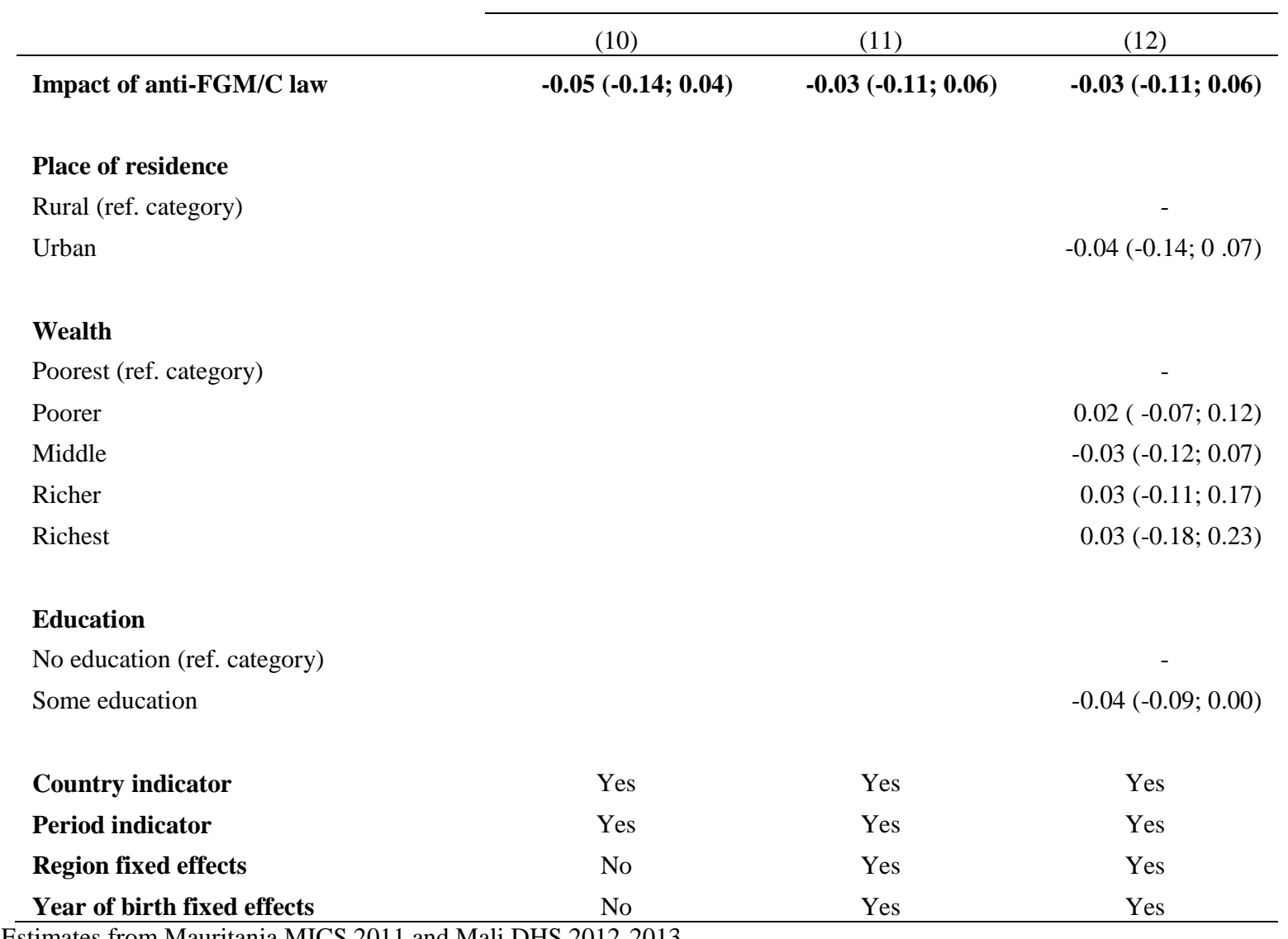

Estimates from Mauritania MICS 2011 and Mali DHS 2012-2013

The $95 \%$ CIs in parentheses are derived from robust SEs clustered at the region level.

$* \mathrm{p}<0.05 * * \mathrm{p}<0.01 * * * \mathrm{p}<0.001$ 
FIGURE 1 Regions of Mali and Mauritania, and estimates of FGM/C prevalence for women aged 15-49

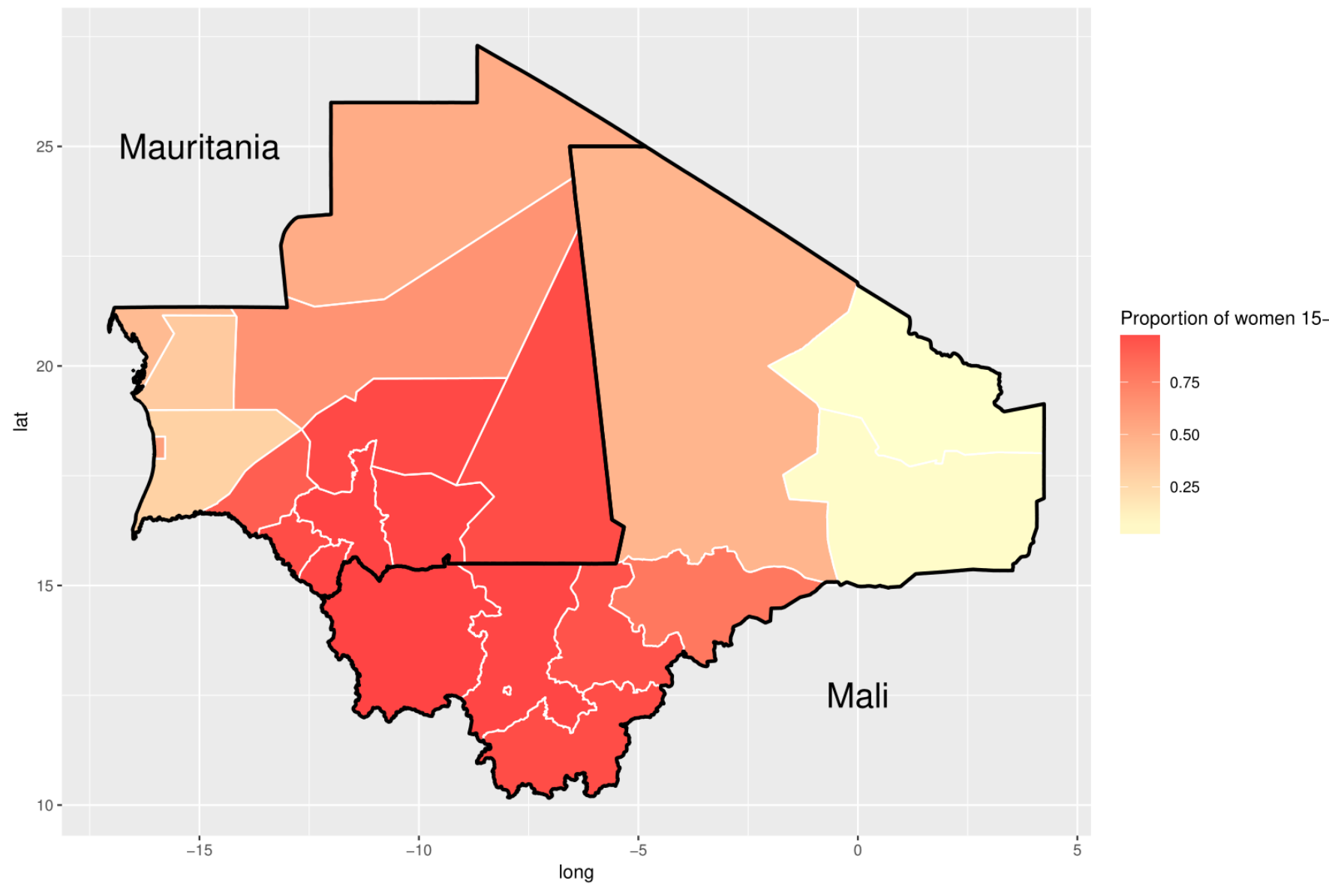

Note: All estimates are weighted to account for survey design and non-response. Results are calculated for the years immediately after the Mauritanian policy was introduced in 2005, and show estimates for Mauritania in 2007 and for Mali in 2006. 
FIGURE 2 Timeline of FGM/C policies in Mali and Mauritania

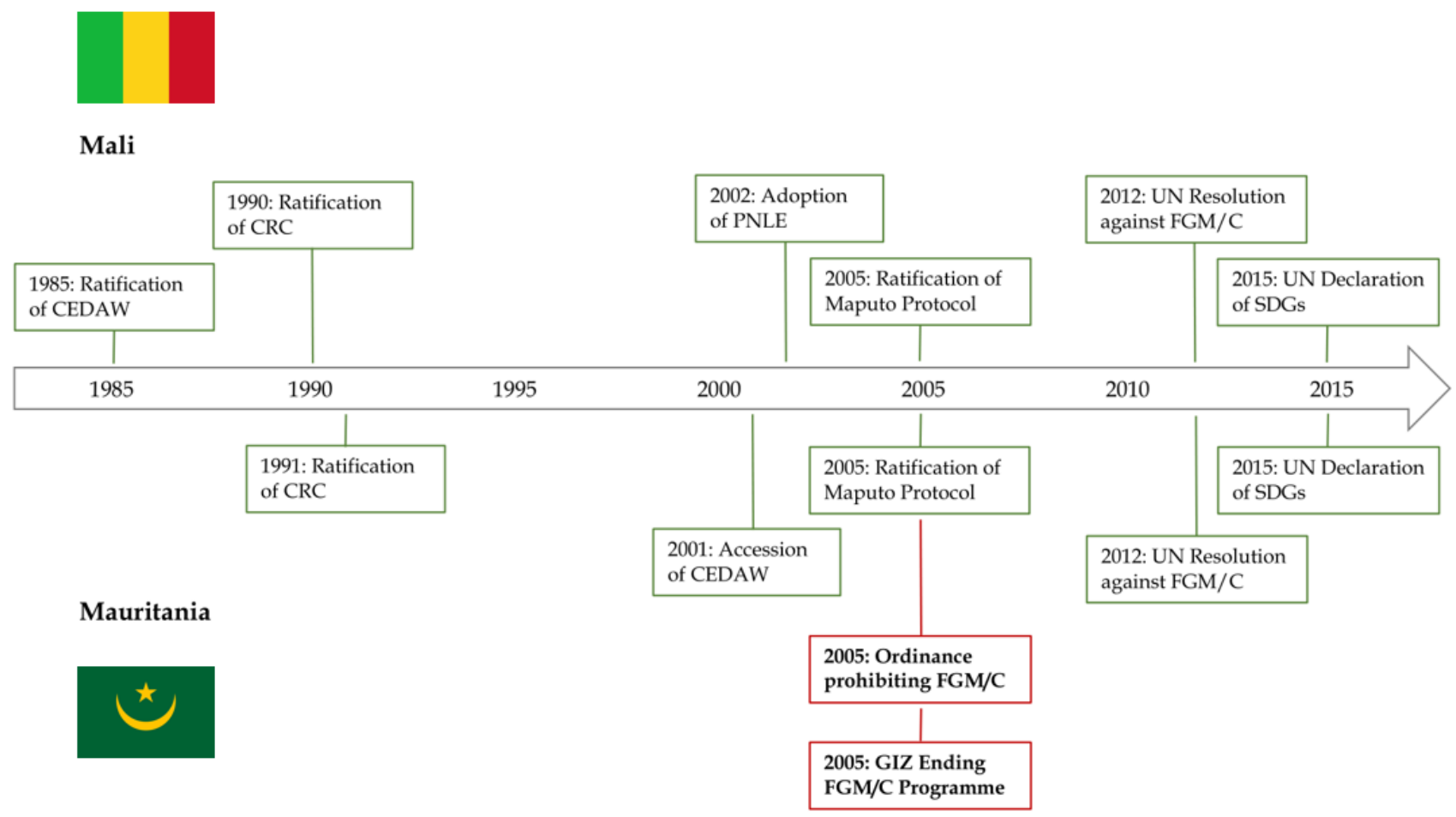

Note: GIZ was specific to bordering regions in the south-east of Mauritania 
FIGURE 3 Trends by birth cohort: Mali and Mauritania

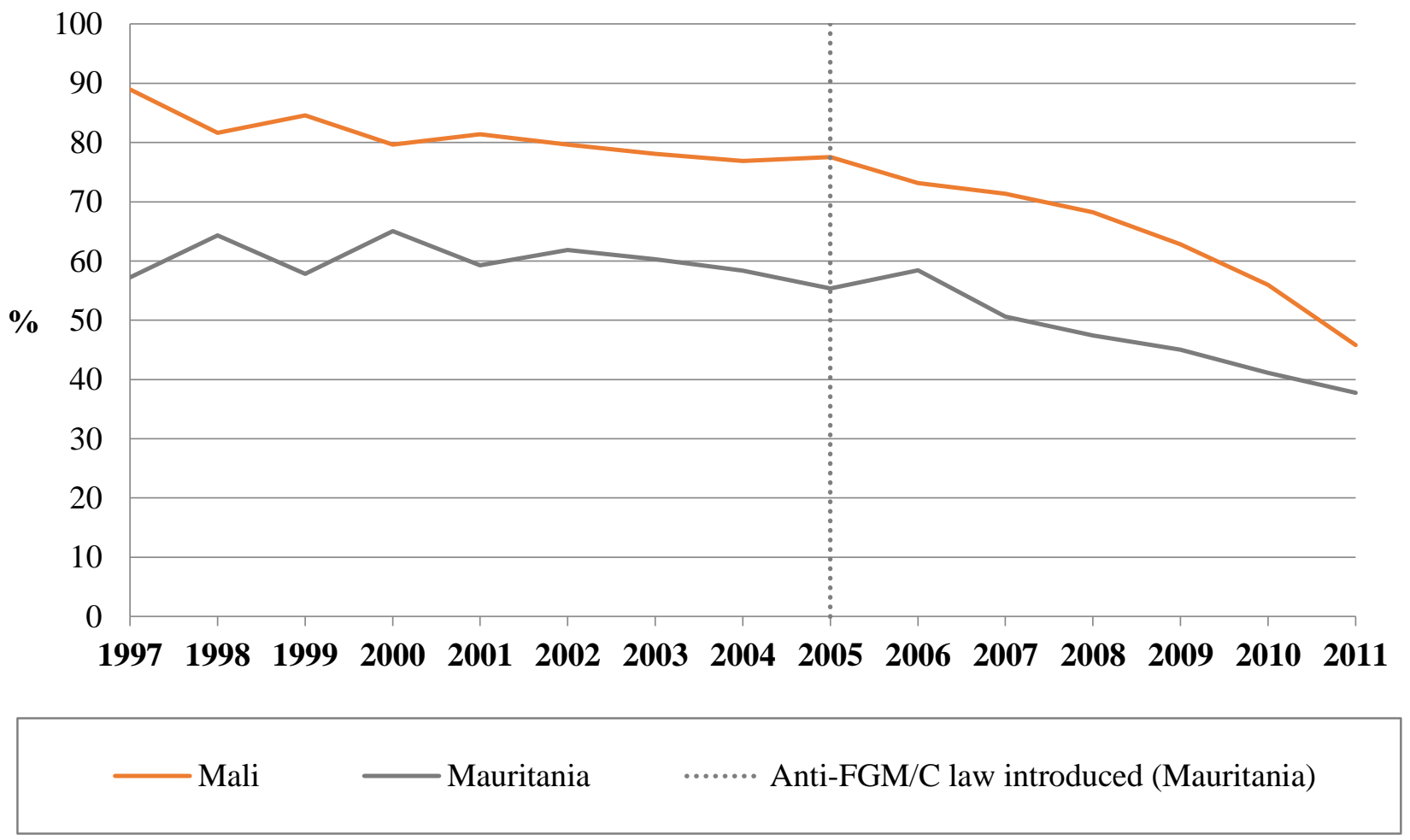

Note: Estimates from Mauritania MICS 2011 and Mali DHS 2012-2013 
FIGURE 4 Trends by birth cohort: high prevalence border regions

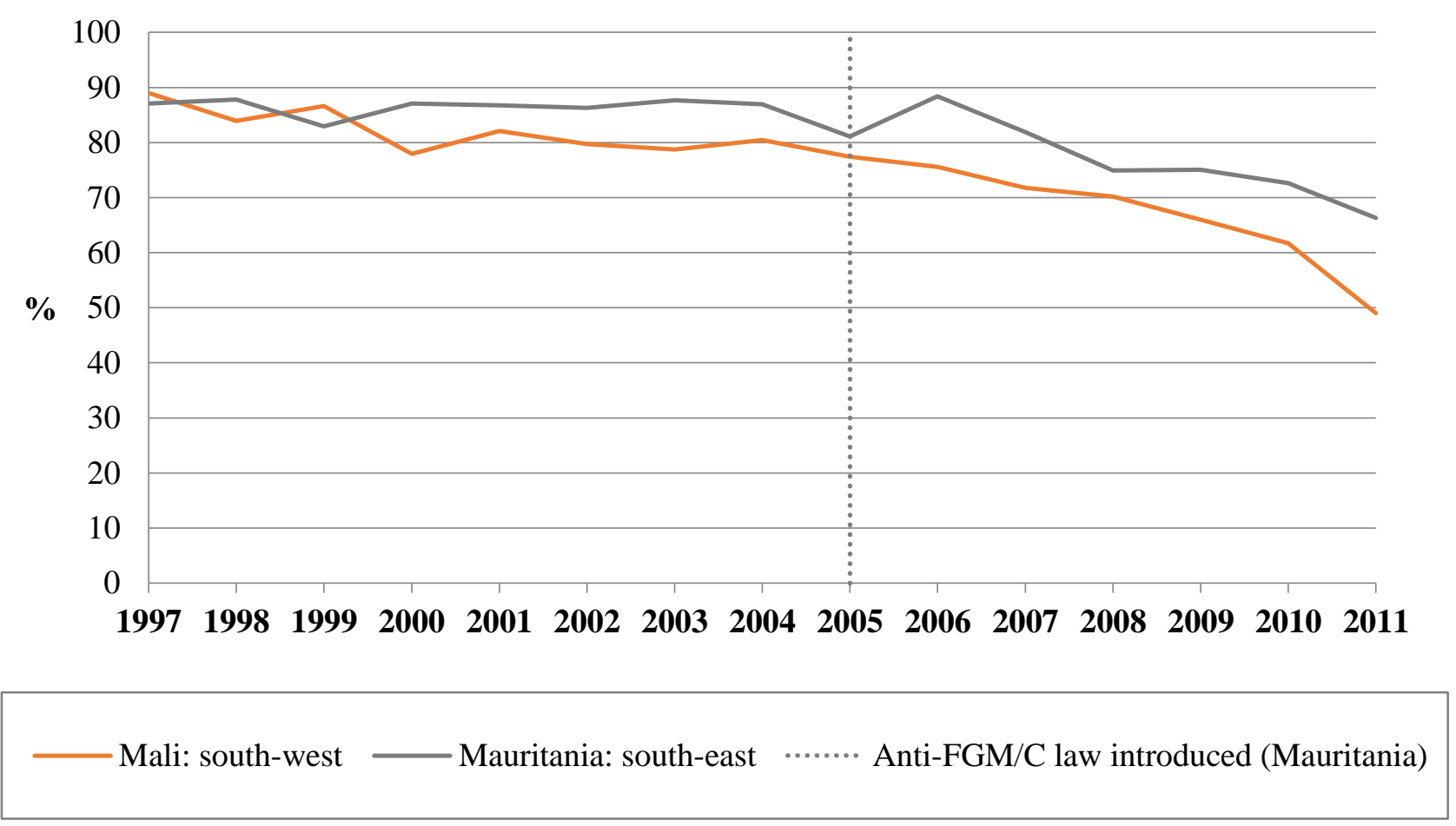

Note: Estimates from Mauritania MICS 2011 and Mali DHS 2012-2013 
FIGURE 5 Trends by year of FGM/C: Mali and Mauritania

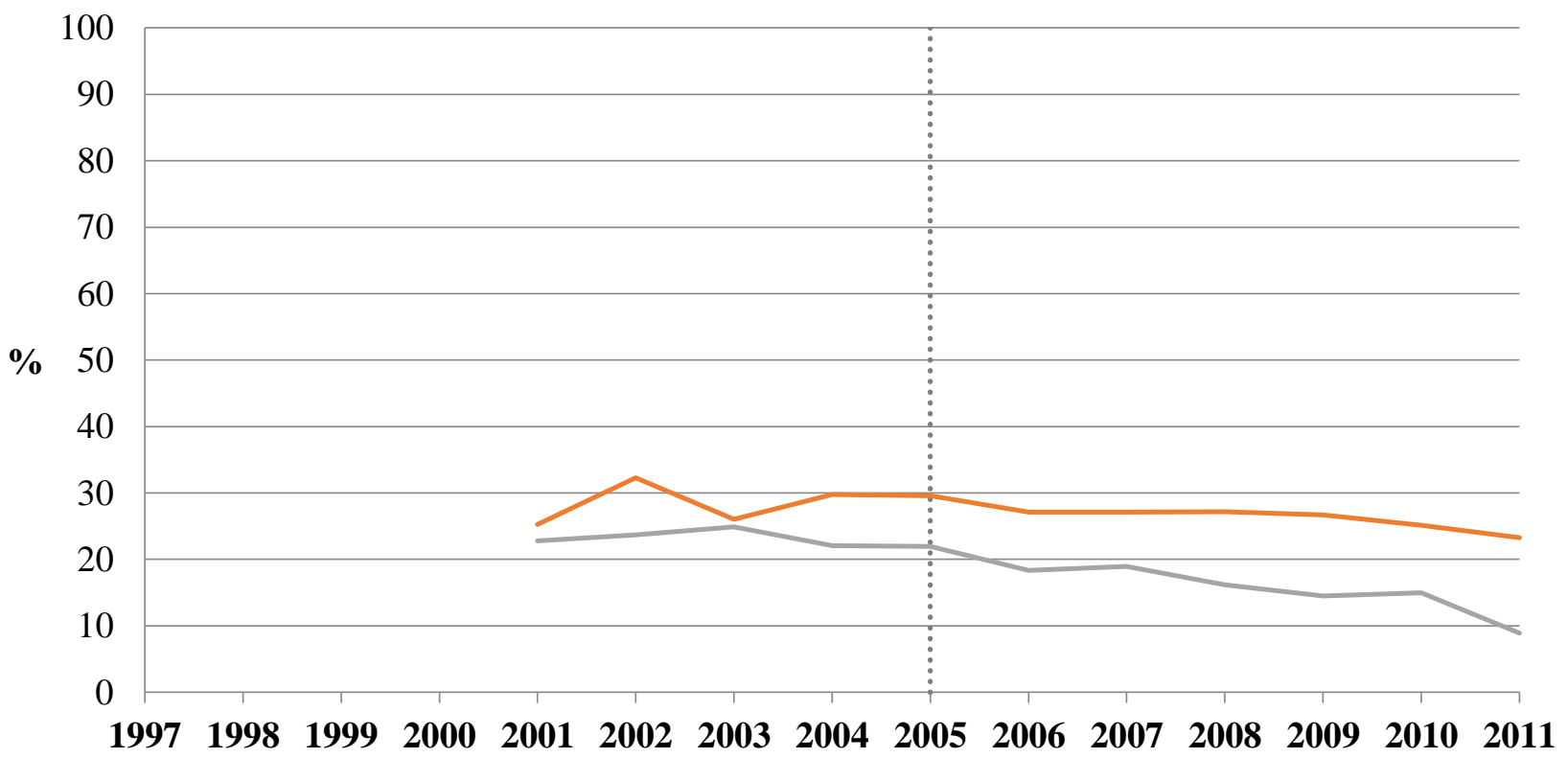

Anti-FGM/C law introduced (Mauritania)

Mali Mauritania

Note: Estimates from Mauritania MICS 2011 and Mali DHS 2012-2013 
FIGURE 6 Trends by year of FGM/C: high prevalence border regions

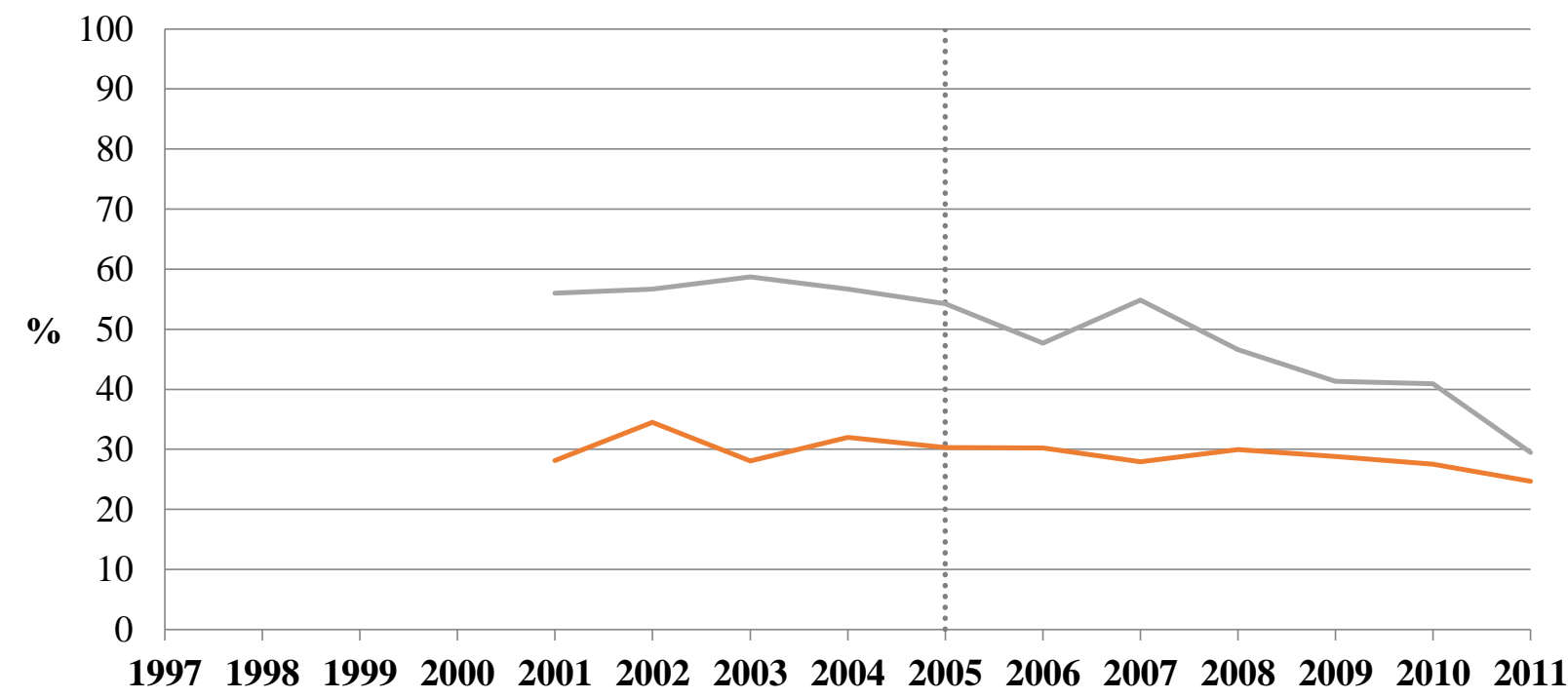

Anti-FGM/C law introduced (Mauritania) Mali: south-west Mauritania: south-east

Note: Estimates from Mauritania MICS 2011 and Mali DHS 2012-2013 